\title{
APUNTES
}

\section{Por una ciencia social descolonial}

RECIBIDO: 29/09/2017

APROBADO: 16/10/2017

César Germaná Cavero

Universidad Nacional Mayor de San Marcos

<cagermana@yahoo.com >

$\mathbf{P}$ ara mí es un significativo honor recibir esta distinción que me consagra como Profesor Emérito de mi Alma Mater, la Universidad más antigua de América. Como rito de admisión y de investidura esta ceremonia realiza de manera simbólica el acto por el cual me reincorporo a la Universidad Nacional Mayor de San Marcos. La magia social de la consagración —como decía el sociólogo Pierre Bourdieu- me da el inmerecido privilegio de pertenecer ahora a la élite académica de profesores destacados. Mi más sincero agradecimiento a las profesoras y a los profesores que propusieron e hicieron posible recibir esta valiosa distinción. En particular quisiera expresar mi reconocimiento a las y los colegas de la Escuela de Sociología con los que he compartido muchos ańos de inquietudes y trabajos orientados a buscar los mejores medios teóricos para comprender el mundo en el que vivimos. ${ }^{1}$

El haberme dedicado a la sociología ha sido una de las elecciones más satisfactorias que he adoptado. Fundamentalmente, porque la sociología me ha ofrecido las herramientas conceptuales más fructíferas para entender la compleja realidad social en la que vivimos; $y$, dado lo que yo era socialmente, para comprender el problemático lugar que he ocupado en el espacio social. En mi largo camino de aprendizaje del oficio de sociólogo he procurado desarrollar la cualidad mental —C. Wright Mills la denominaba

$1 \quad$ Palabras de agradecimiento en la ceremonia del otorgamiento de la distinción de Profesor Emérito de la Universidad Nacional Mayor de San Marcos, 2017.

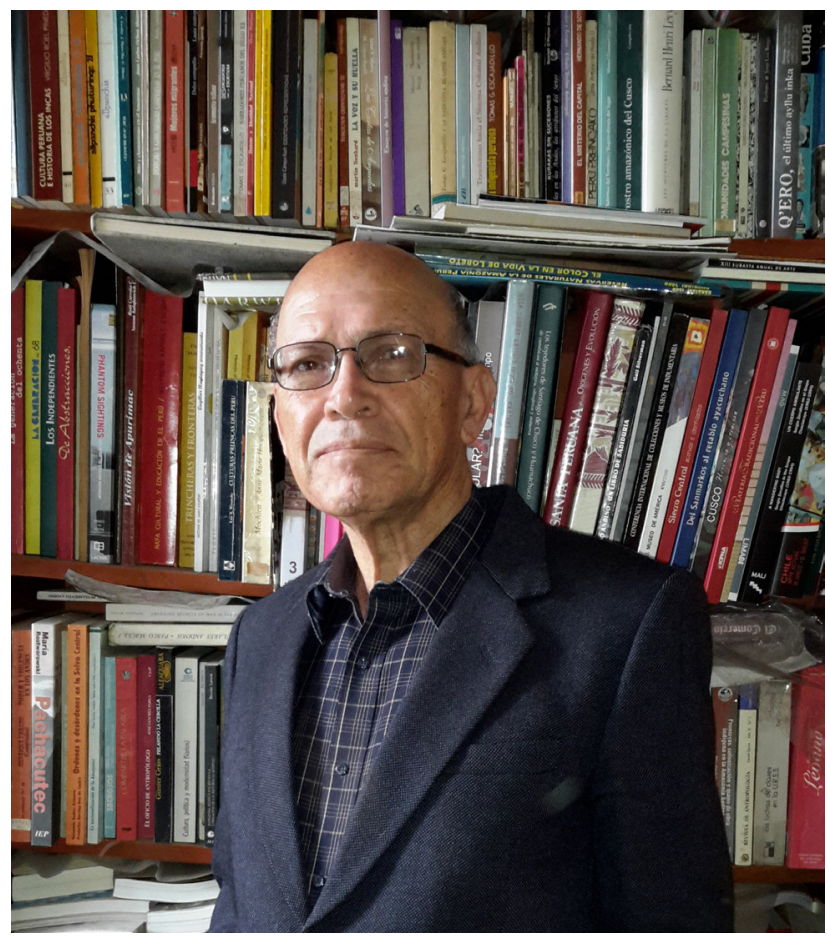

Dr. César Germaná Cavero.

imaginación sociológica - que según él consiste en «usar la información y [...] desarrollar la razón para conseguir recapitulaciones lúcidas de lo que ocurre en el mundo y de lo que quizás está ocurriendo dentro [de cada uno de nosotros]». De suerte que cada una de nuestras vidas puede ser observada "como puntos diminutos de las intersecciones de la biografía y de la historia dentro de la sociedad» (Mills, 1964: 25 y 27). De esta manera, la sociología me ha permitido, si 
bien no sentirme cómodo en el mundo, por lo menos encontrarle un determinado sentido.

Además, he sido muy afortunado al haber podido desarrollar mi quehacer sociológico en una universidad pública y de la calidad de nuestra Universidad de San Marcos. Primero como alumno en la década de 1960 y, posteriormente, como profesor desde 1970. De mis maestros — como Augusto Salazar Bondy, José Matos Mar, Javier Pulgar Vidal, Carlos Araníbar y, sobre todo, Aníbal Quijano, entre otros- aprendí a adoptar una actitud intelectual abierta, crítica y rigurosa que me ha permitido participar activamente en los debates sobre el rol de la sociología y las ciencias sociales así como sobre el papel de la universidad en la sociedad. Esos debates fueron muy productivos y esclarecedores y se fueron enriqueciendo con las polémicas - a veces excesivamente agresivas - con los colegas en las diversas coyunturas por las que ha atravesado la universidad en los últimos 45 años. Además, ha sido muy instructiva y fructífera mi relación con los alumnos de las diversas promociones. He tenido excelentes alumnas y alumnos que con sus demandas, preguntas y opiniones me han hecho reflexionar e investigar sobre diversos aspectos de nuestra realidad histórico-social y me han llevado a profundizar en los diferentes enfoques teóricos de la sociología y las ciencias sociales.

En mi itinerario sociológico he tratado de seguir —en la medida de mis modestas posibilidadesla recomendación que en los inicios del siglo XIX planteaba el conde de Saint-Simon, uno de los fundadores de la sociología y de la ciencia social, en su autobiograbía Vida de Saint-Simon escrita por él mismo, para quienes quisieran dedicarse al estudio de la vida social de los seres humanos:

$1^{\circ}$ Llevar, mientras la edad lo permita, la vida más original y activa que sea posible.

$2^{\circ}$ Adquirir conocimientos, con cuidado, de todas las teorías y de todas las prácticas.

$3^{\circ}$ Recorrer todo las clases sociales y situarse personalmente en las posiciones sociales más dispares, e incluso crear relaciones que jamás hayan existido.

$4^{\circ}$ Por último, emplear la vejez para resumir las observaciones sobre los efectos resultantes de las propias acciones, tanto en los otros como en uno mismo, y de dicho resumen establecer los principios.

Ahora, en la vejez, después de haber tenido tantas y tan diversas experiencias y haber examinado numerosas teorías sobre el ser y el hacer social quisiera explorar, de manera todavía provisoria, algunos principios, que creo fundamentales, para enfrentar los actuales desafíos que encara la sociología y las ciencias sociales en el Perú y en América Latina.

Lo primero que tenemos que tener en cuenta es que la época en la que nos encontramos no tiene las características del momento en que se construyeron históricamente las ciencias sociales. Las ciencias sociales surgieron en Europa y en Estados Unidos entre 1850 y 1950 periodo de relativa estabilidad y consolidación del sistema-mundo moderno y sobre la base de un generalizado optimismo social centrado en el progreso. En cambio, en la época actual, el patrón de poder que surgió hace quinientos años, con la conquista ibérica de lo que posteriormente se llamará América, se ha hecho inestable, ha llegado a un punto de bifurcación y ha entrado a un periodo caótico y de transición. Los indicadores más significativos de este convulso momento histórico se encuentran en las crecientes dificultades en el proceso de acumulación incesante de capital, motor del sistema capitalista; la paulatina desnacionalización y desdemocratización del Estadonación; y, lo que quizás constituye la advertencia más peligrosa para la sobrevivencia de la especie humana, la profunda crisis ecológica que estamos sufriendo.

También la teoría social de la era clásica ha llegado a un punto de bifurcación hacia fines de la década de 1960 e inicios de la década de 1970. Ese momento marca el fin de las certidumbres en nuestras maneras de conocer la realidad, como ha señalado con tanto acierto el premio Nobel de química Ilya Prigogine. Se empieza a cuestionar las premisas newtonianas-cartesianas sobre las que se construyeron las ciencias sociales y se abre un amplio debate sobre su necesaria reorganización donde se despliegan nuevos horizontes y nuevas preguntas, pero también se asume nuevos riesgos. En este sentido se trata de un momento privilegiado para la sociología y las ciencias sociales que nos plantea significativos desafíos.

En un mundo incierto, donde se están produciendo rápidas y profundas transformaciones en todos los ámbitos de la vida social, han surgido numerosas teorías en las ciencias sociales orientadas a dar cuenta de cómo se produce y reproduce la existencia social. Creo que uno de los enfoques teóricos más fructíferos $y$ prometedores para comprender el mundo en el que vivimos y su transformación se encuentra en la perspectiva de análisis de la colonialidad/ 
descolonialidad del poder propuesta por Aníbal Quijano, científico social peruano y Profesor Emérito de nuestra casa de estudios. Aníbal Quijano ha tenido la suficiente osadía intelectual como para ir en contra del hegemónico pensamiento eurocéntrico y, desde de la periferia del sistema-mundo colonial/moderno, plantear categorías y conceptos que permiten establecer otra mirada sobre la realidad histórico-social que revela una configuración epistemológica que conforma una episteme descolonial. Instaura una perspectiva cognitiva - una manera de conocer y producir conocimiento sobre la vida social de los seres humanos- que establece las bases de una profunda revolución epistemológica. Se puede considerar que el principio de la colonialidad del poder constituye un golpe de estado teórico capaz de llevar adelante una ruptura epistemológica con el pensamiento eurocéntrico que se fue construyendo en Europa desde el siglo XVII y que se impuso como la perspectiva de conocimiento hegemónica en el sistema-mundo colonial/moderno. La episteme eurocéntrica tiene como núcleo central la racionalidad cognitivo-instrumental centrada en el principio cartesiano de la simplificación y en el principio newtoniano de la estabilidad de sistemas deterministas regidos por leyes válidas universalmente. La episteme descolonial cuestiona los principios del eurocentrismo y establece los fundamentos de una nueva estructura de saber. Teniendo como punto de partida los análisis y reflexiones de Aníbal Quijano, me gustaría explorar algunos de los elementos principales para la construcción de una emergente ciencia social descolonial.

Considero que la crítica del poder constituye la base epistemológica sobre la cual se configura una ciencia social descolonial, en la medida en que el poder aparece como el principio organizador de los diferentes ámbitos de la vida social. En la actualidad, cuando el pensamiento social corresponde preferentemente a necesidades tecnocráticas y la educación deja de estar orientada al logro de la formación integral de seres humanos, para convertirse en el adiestramiento de «recursos humanos» o de "capital humano» de acuerdo con las necesidades del mercado, sacar a luz las relaciones de poder que determinan la convivencia social constituye el punto de partida para la construcción de un conocimiento descolonial. Una de las características más engańosas del poder es esconderse y actuar indirectamente, o disfrazarse al presentarse como si fuera una cosa. Más bien, para poder examinarlo y comprenderlo, y cuestionarlo, es necesario considerarlo como un tramado de relaciones sociales. Como señala Quijano, «el poder es un espacio y una malla de relaciones sociales de explotación / dominación / conflicto articuladas, básicamente, en función y en torno de la disputa por el control de los siguientes ámbitos de existencia social: 1) el trabajo y sus productos; 2) en dependencia del anterior, la «naturaleza» y sus recursos de producción; 3) el sexo, sus productos y la reproducción de la especie; 4) la subjetividad y sus productos materiales eintersubjetivos, incluido el conocimiento; 5) la autoridad y sus instrumentos, de coerción en particular, para asegurar la reproducción de ese patrón de relaciones sociales y regular sus cambios». Desde este punto de vista, lo que llamamos sociedad no puede ser considerada sino como una totalidad articulada por las relaciones de poder. En consecuencia, conocer sus procesos de organización y transformación implica develar la estructura de poder que le da forma, esto es, cómo se organizan las relaciones sociales de dominación y conflicto.

En este sentido, la categoría de totalidad es fundamental para poder aprehender la realidad histórico-social. Pero para que sea fructífero este concepto es necesario diferenciarlo tanto de la imagen sistémica del estructuralismo como de la imagen organicista del materialismo histórico. Se trata de considerarla como una totalidad estructuralmente heterogénea e histórica. «La idea de totalidad histórica —dice Quijano- excluye la posibilidad de que una lógica única presida la constitución y el proceso histórico de una totalidad social concreta, puesto que ésta es históricamente heterogénea y no puede sino estar integrada por varias y diversas lógicas. Ellas se articulan, ciertamente, producen una estructura y se ordenan en torno de una lógica de conjunto y en este sentido forman también una continuidad; pero, al mismo tiempo, en el mismo movimiento, no pueden dejar de ser diversas y discontinuas. Se trata de la articulación de elementos diversos, inclusive antagónicos, discontinuos, en una estructura conjunta, la cual, por lo mismo, no puede tener ni finalidad, ni sentido, ni secuencias, anteriores a su propia historia».

Estas totalidades estructuralmente heterogéneas e históricas forman patrones de poder puesto que el poder constituye la matriz que organiza la vida social. Podemos considerar al patrón de poder como un sistema social complejo e histórico. Es un sistema social complejo en la medida en que articula los diferentes 
ámbitos de las relaciones sociales que se interdefinen mutuamente y donde su desenvolvimiento es el resultado de la lucha — dominación y conflicto- de las diferentes fuerzas que buscan organizarlo para su propio beneficio. $Y$ es histórico en cuanto a que tiene un momento en el que surge, después tiene un largo proceso de desarrollo y consolidación, para finalmente llegar a un punto de bifurcación a partir del cual el sistema se hace inestable y caótico para erosionarse y dar paso a otro u otros patrones de poder.

En el análisis de los patrones de poder es fundamental el principio de la especificación histórica de las relaciones sociales. Este principio permite comprender la especificidad del patrón de poder que surgió con la conquista ibérica de América. Lo distintivo de este patrón de poder es la colonialidad -entendida como la racialización de las relaciones sociales- que es constitutiva del patrón de poder mundial capitalista eurocentrado. Lo noción de raza aparece como la naturalización de las relaciones de dominación que establecieron los conquistadores sobre las poblaciones nativas. Da cuenta de una alquimia social pues una relación de poder, por lo tanto social, se convierte en el imaginario dominante en un hecho biológico. En este sentido, la noción de raza se transforma en una categoría epistémica que permite dar cuenta del control de las formas de conocer y de producir conocimientos. Los saberes de los pueblos originarios, considerados racialmente inferiores, fueron marginados, reprimidos, subalternizados y se impuso el predominio de los saberes eurocéntricos.

Con la categoría de totalidad estructuralmente heterogénea e histórica es posible establecer la crítica del patrón de poder cuya especificidad está dada por la colonialidad. A partir de esta crítica, se pueden encontrar los elementos que configuran una ciencia social descolonial que tiene como núcleo central una racionalidad alternativa a la racionalidad cognitivo-instrumental del eurocentrismo. Se trata de la racionalidad de las relaciones sociales centradas en la solidaridad entre los seres humanos, libres e iguales, y de la armonía entre los seres humanos y la naturaleza. Si bien es cierto que se trata de un saber racional, también es cierto que posibilita establecer fructíferas mezclas epistemológicas con los saberes populares y tradicionales de los pueblos originarios y afrodescendientes. Se trata de una racionalidad que articula el logos y el mito como se muestra de manera tan creativa en la obra de José Carlos Mariátegui.
Desde este punto de vista, es inconducente la arbitraria separación entre lo político, lo económico y lo sociocultural; más bien, estos ámbitos de la vida social no pueden ser sino momentos de una unidad compleja que es la totalidad histórica. Además, de acuerdo a esta perspectiva, no tendría ninguna justificación epistemológica la especialización en disciplinas del conocimiento social, tal como resultó de la construcción histórica de las ciencias sociales en Europa en el siglo XIX; la única especialización fructífera sería por problemáticas específicas o campos de investigación, que fundaría un saber transdisciplinario. Asimismo, la superación del saber eurocéntrico conlleva el rompimiento de los límites establecidos por la tesis de las dos culturas: la cultura científica y la cultura humanística. Si el conocimiento científico se ha preocupado exclusivamente por la búsqueda de la verdad mediante procedimientos empíricos y el conocimiento humanístico ha discutido los valores éticos y estéticos, la perspectiva del análisis de la descolonialidad del poder plantea la necesidad de que el conocimiento, en el mismo proceso de su producción, sea a la vez verdadero, bueno y bello.

La ciencia social descolonial corresponde a un pensamiento crítico utopístico porque busca examinar la realidad social desde el punto de vista de lo que debería ser otro mundo posible, cuyo desenvolvimiento se encuentra bloqueado por la actual estructura de poder global. "Lo posible -dice I. Progogine- es más rico que lo real» (Prigogine, 2001: 64). Si bien esta afirmación se refiere al análisis de la naturaleza, con mayor razón es aplicable a la exploración de la realidad social. Un orden social más democrático e igualitario es posible y las ciencias sociales tienen que tener presente este objetivo en sus análisis e iluminar las opciones históricas del futuro. Además, no se trata de un pensamiento que busque construir una utopía sino de establecer un horizonte histórico de sentido basado en una racionalidad solidaria. Este horizonte se puede cristalizar en el proyecto del Bien vivir (suma qamańa o sumak kawsay): «Un complejo de prácticas sociales orientadas a la producción y a la reproducción democráticas de una sociedad democrática», como lo define Aníbal Quijano.

La perspectiva de una ciencia social descolonial pone en evidencia la vigencia y trascendencia del pensamiento de José Carlos Mariátegui. En el Amauta se encuentran los puntos de partida para un análisis crítico -no eurocéntrico- de la realidad social 
y de su transformación. En el periodo de transición que estamos viviendo la obra de Mariátegui leída de manera desfetichizada es sumamente fructífera para avanzar en el proyecto de la descolonialidad del poder. «El pasado incaico — escribió Mariátegui- ha entrado en nuestra historia, reivindicado no por los tradicionalistas sino por los revolucionarios. En esto consiste la derrota del colonialismo [...]. La revolución ha reivindicado nuestra más antigua tradición» (Mariátegui, 1994: I, 326). Mariátegui llamó a esta tradición "comunismo incaico». Pero no se trataba — para él— de volver al pasado pre-colonial, sino de entender las raíces indígenas del futuro; es decir, no buscaba la conservación del pasado, sino, más bien, aspiraba a la realización de las esperanzas del pasado. En este sentido, sus reflexiones sobre el socialismo pueden vincularse con las actuales propuestas de los pueblos originarios andinos y amazónicos del Buen Vivir. El núcleo central del este proyecto está dado por la descolonialidad de las relaciones de poder que se establecieron con la conquista europea de América: la igualdad en las relaciones de género, la reciprocidad en las relaciones de trabajo, el autogobierno en las relaciones de autoridad, la interculturalidad -o diálogo de saberes - en las relaciones intersubjetivas y, lo que con toda seguridad constituye un planteamiento fundamental, que los seres humanos sepamos estar atentos a una "escucha poética» de la naturaleza, que es una realidad viva y no un mundo silencioso y monótono. Se trata de un proceso y de un programa que hunde sus raíces en las tradiciones andinas; Mariátegui lo entrevió y lo exploró y con su propuesta de socialismo indo-americano buscó la restitución del sentido histórico de la sociedad peruana (Germana, 1995). No se trataba de una utopía, sino de un nuevo horizonte histórico de sentido. Expresaba las experiencias y el aprendizaje milenario que los pueblos indígenas han mantenido a pesar de tantos siglos de sometimiento y humillación e instauraba un proyecto para construir un orden social bueno, verdadero y bello que llevaría al reencantamiento del mundo que la colonialidad/modernidad había desencantado.

La construcción de una ciencia social descolonial constituye una alternativa viable a la versión newtoniana-cartesiana de la ciencia social eurocéntrica. La descolonialidad de las ciencias sociales implica una racionalidad basada en la solidaridad y cuestiona las premisas con las se construyeron históricamente. Para esta manera de producir conocimientos, de un lado, no existe simetría temporal entre pasado y futuro sino que la vida social está atravesada por la flecha del tiempo; y, de otro lado, no busca simplificar la realidad sino explicar lo complejo. En consecuencia, la ciencia social descolonial establece una perspectiva de conocimiento, a la vez intelectual, moral y política que, en aspectos fundamentales, constituye un proyecto poseedor de características prometedoras para la elaboración de teorías generales o específicas sobre la realidad histórico- social. Teorías generales sobre los ámbitos más amplios del actual patrón mundial de poder, de su organización, de su crisis estructural y de las alternativas históricas que pueden remplazarlo; y teorías específicas sobre ámbitos más circunscriptos de ese patrón histórico de poder.

Señor Rector, la distinción que con tanta generosidad se me otorga me compromete a seguir trabajando para que la sociología y las ciencias sociales en nuestra universidad tengan un lugar relevante en el Perú y en América latina.

Muchas gracias. 